\title{
Upper limb motor function at 5000 metres: determinants of performance and residual sequelae
}

\author{
Eli Silber
}

\begin{abstract}
Little is known about the effects of age and symptoms of acute mountain sickness and the potential benefit of short term acclimatisation on fine motor performance at altitude. There is uncertainty about whether time spent at altitude results in permanent neurological sequelae. Nine hole pegboard tests were performed on a group of trekkers at sea level $(n=61)$, after ascending to Kanchenjunga base camp $(5100 \mathrm{~m} ; \mathrm{n}=46)$, and 20 weeks after return to sea level $(n=43)$. Comparison of baseline and altitude times showed a mean slowing from 36.2 to 39.0 seconds, a $7.8 \%$ deterioration in performance $(p<0.0001)$, which was greatest in subjects aged 50 years or older $\left(\begin{array}{llll}5.04 & v & 1.93 & \text { seconds, }\end{array}\right.$ $p=0.017$ ), those tested within 24 hours of arrival at $5100 \mathrm{~m}(4.75$ seconds, $13.3 \% v$ 0.48 seconds, $1.3 \% \mathrm{p}<0.001$ ), and persons experiencing symptoms of acute mountain sickness $(p=0.012)$, each of which were independent determinants of deterioration. Repeat pegboard testing at sea level after 20 weeks showed no significant change compared with baseline $(p=0.68)$. This confirms the deleterious effects of altitude on fine motor function, emphasises the benefit of acclimatisation, and suggests that older persons and those with symptoms of acute mountain sickness are particularly susceptible. The risk of long term motor dysfunction after exposure to these relatively moderate altitudes seems to be small.

(F Neurol Neurosurg Psychiatry 2000;69:233-236)
\end{abstract}

Department of Clinical

Keywords: psychomotor testing; altitude; hypoxia

Neurosciences,

Hodgkin Building,

Guy's, King's and St

Thomas' School of

Medicine, King's

College, London

SE1 9RT, UK

E Silber

eli.silber@kcl.ac.uk

Received 13 October 1999 and in revised form

13 March 2000

Accepted 23 March 2000 these altitudes. Motor dysfunction is likely to be due to a combination of disturbances in visual, motor, and cerebellar processing. However, little is known about the determinants of psychomotor functioning at altitude, in particular age and symptoms of acute mountain sickness. Previous studies have investigated predominantly younger persons, but this may not be appropriate in the light of the growing number of older people who spend time at altitude. Few studies have assessed the potential for short term adaptation of neurological function at altitude. There are conflicting reports as to whether exposure to altitude results in long term neurological sequelae. ${ }^{13}$

This study was therefore conducted to investigate the effect of age, sex, symptoms of acute mountain sickness, and hypoxia on psychomotor function in a group of trekkers at $5100 \mathrm{~m}$. It also assessed the potential effects of short term acclimatisation on motor function at altitude and whether exposure to altitude resulted in residual deleterious effects on psychomotor function.

\section{Methods}

This study investigated members of an expedition to Kanchenjunga base camp (5100 m) in eastern Nepal in 1998. The objectives of the expedition included medical research, with subjects giving consent to participate in this project. Some team members attempted to climb Kanchenjunga (reaching over $7000 \mathrm{~m}$ ) and other peaks over $6000 \mathrm{~m}$ in the area. Expedition members followed recommendations by not ascending by more than $300 \mathrm{~m} /$ day and took rest days to aid acclimatisation.

Pegboard tests assess a composite of upper limb psychomotor function. The nine hole pegboard was chosen as it is a standardised test, convenient to carry and perform. It is sensitive $^{4}$ and is the recommended test for assessing upper limb function in multiple sclerosis. $^{5}$ Testing was performed while seated on a stable surface, with adequate lighting and in moderate weather conditions in subjects who were adequately fed and hydrated. A combined score of the mean of two attempts with the dominant and non-dominant hand is reported. 
Comparison of mean nine hole pegboard test results in 46 trekkers tested at baseline and $5100 \mathrm{~m}$

\begin{tabular}{|c|c|c|c|c|c|c|}
\hline & $n$ & Baseline & Altitude & Time difference $(s)^{\star}$ & Deterioration $(\%) \dagger$ & p Value \\
\hline \multicolumn{7}{|l|}{ Age: } \\
\hline$<50 \mathrm{y}$ & 33 & 34.85 & 36.80 & 1.93 & $5.8(2.0-9.5)$ & 0.004 \\
\hline$\geqslant 50 \mathrm{y}$ & 13 & 39.43 & 44.48 & 5.04 & $13.0(6.0-20)$ & 0.002 \\
\hline $\mathrm{p}$ Value & & $<0.0001$ & $<0.0001$ & 0.017 & 0.05 & \\
\hline \multicolumn{7}{|c|}{ Period spent at $5100 \mathrm{~m}$ before testing: } \\
\hline$<24 \mathrm{~h}$ & 25 & 36.14 & 40.89 & 4.75 & $13.3(9.0-17.6)$ & $<0.0001$ \\
\hline 1-4 days & 21 & 36.23 & 36.71 & 0.48 & $1.3(-2.6-5.3)$ & 0.5 \\
\hline p Value & & 0.9 & 0.005 & 0.0001 & $<0.001$ & \\
\hline Total $\ddagger$ & 46 & $36.18(35.21-37.16)$ & $38.99(37.44-40.53)$ & $2.81(1.61-4.00)$ & $7.8(4.5-11.2)$ & $<0.0001$ \\
\hline
\end{tabular}

*Altitude-baseline (positive number denotes deterioration).

†Mean $(95 \% \mathrm{CI})$ time difference/baseline $\times 100$.

$\ddagger$ Mean $(95 \% \mathrm{CI})$.

Baseline data were obtained on all potential test subjects at sea level 3 months before the expedition. During the trip, subjects recorded oxygen saturation $\left(\mathrm{SaO}_{2}\right)$ at rest with a portable pulse oximeter and maximal and tidal breath holding times, twice daily. Symptoms of acute mountain sickness were recorded using a questionnaire based on the Lake Louise score. ${ }^{6}$ All available subjects were assessed on reaching $5100 \mathrm{~m}$ before any significant further ascents; testing was not repeated at altitude because of a potential practice effect, but was performed again on all expedition members attending a reunion at sea level 20 weeks after their return.

Data were analysed using STATA version 5.1 (Stata corporation, TX, USA) and GraphPad Prism 2.01 (GraphPad Software, CA, USA). To correct for expected differences in testing times between older and younger subjects, a percentage change in performance time was calculated using the following formula: ((pegboard time at altitude-pegboard time at baseline)/pegboard time at baseline)x100. Results are expressed as absolute values as well as the percentage change in performance but statistical analysis was based on the absolute values. Comparison of means was performed using $t$ tests, paired $t$ tests, and analysis of variance (ANOVA) where appropriate. Continuous variables were compared using Pearson correlation coefficients. To control for possible confounding, a multiple linear regression analysis was performed: all explanatory variables with a level of significance of $\mathrm{p}<0.1$ on univariate analysis were included.

\section{Results}

Sixty one potential subjects were assessed at baseline; of these, 46 were available for retesting at $5100 \mathrm{~m}$ and 43 after return. The mean age at baseline was 40.4 years (range 18.4-67.9 years) with 13 aged 50 years and over. There was no difference in mean age between subjects tested $(n=46)$ and those not tested $(\mathrm{n}=15)$ at altitude $(40.3 v 40.4$ years, $\mathrm{p}=0.99)$ or those tested $(\mathrm{n}=43)$ or not tested $(\mathrm{n}=18)$ on return $(40.7$ v 39.5 years, $\mathrm{p}=0.73)$. However, all of the subjects not available for retesting at altitude and $17 / 18$ of those not retested after 20 weeks were men.

At baseline, the mean pegboard time of subjects aged 50 years or more was significantly slower than in those under 50 (39.43 $v 35.10$ seconds; $\mathrm{p}<0.0001)$. The mean pegboard time in men was slower than in women (36.63v
34.29 seconds; $p=0.01)$. Linear regression showed age $(p<0.001)$ and sex $(p=0.02)$ to be independent determinants of slowing in pegboard time.

The overall effects of altitude and effects of age and time of testing in the 46 subjects retested at altitude are summarised in the table. There was a mean slowing of 2.81 seconds, corresponding to a $7.8 \%$ deterioration in performance $(p<0.0001)$. The deterioration was similar in men and women (3.17 seconds, $8.7 \%$ v 2.11 seconds, $6.2 \%, \mathrm{p}=0.40)$. Subjects aged 50 years or older had a significantly greater deterioration in performance compared with their initial baseline compared to the younger group $(p=0.017)$. Testing was performed on 25 subjects within 24 hours and in the remainder up to 4 days after arrival. Persons tested within 24 hours had a significantly greater mean deterioration compared with those assessed later $(p=0.0001)$. There were no differences in mean baseline performance between these two groups.

Pegboard times were influenced by symptoms of acute mountain sickness on the day of testing. Those with moderate $(n=7$; score $1-3)$ and more severe $(n=6$; score $4+$ ) symptoms had a significant deterioration in performance (4.25 seconds, $12.3 \%$, and 6.26 seconds, $18.4 \%$ respectively) compared with the 1.75 seconds $(4.5 \%)$ deterioration in asymptomatic subjects $(n=28$; score 0$)(p=0.03$ by ANOVA). There was no significant difference in mean baseline performance between these groups $(36.99,35.49$, and 33.98 seconds; $p=0.11)$ and there was no difference in mean ages in the groups with different acute mountain sickness scores $(42.7,38.1$, and 41.1 years; $p=0.71)$.

As expected, there were significant differences in pegboard times between the dominant and non-dominant hand (17.59 $v 18.59$ seconds; $\mathrm{p}<0.0001)$ which persisted at altitude (18.93 v 20.06 seconds; $\mathrm{p}<0.0001)$. There was, however, no significant difference in the change in performance at altitude compared with baseline between the dominant and non-dominant hand (1.33 seconds, $7.9 \% v$ 1.47 seconds, $8.0 \%$ deterioration; $\mathrm{p}=0.64)$.

Performance at altitude did not show a significant correlation with the person's $\mathrm{SaO}_{2}$ on the day of testing (mean $82.1 \%, r=-0.23$, $\mathrm{p}=0.15, \mathrm{n}=40$ ) or the percentage difference in $\mathrm{SaO}_{2}$ between baseline and on day of testing (mean deterioration of $14.0 \%, r=-0.12$, $\mathrm{p}=0.51, \mathrm{n}=33$ ). Analysis of only the subgroups 
with moderate or severe symptoms of acute mountain sickness $(n=13)$ again showed no correlation between pegboard performance and $\mathrm{SaO}_{2}(r=-0.52, \mathrm{p}>0.05)$. Similarly, there was no significant correlation between subjects' maximum breath holding times on the day of testing (mean 36 seconds, $r=-0.30$, $\mathrm{p}=0.22, \mathrm{n}=19)$ or changes when compared with sea level (mean deterioration 47 seconds, $53.3 \%)$ and pegboard performance $(r=-0.06$, $\mathrm{p}=0.80, \mathrm{n}=19)$.

Multiple linear regression showed that age 50 years or older $(\mathrm{p}=0.034)$, testing within 24 hours of arrival at $5100 \mathrm{~m}(\mathrm{p}=0.008)$, and symptoms of acute mountain sickness $(p=0.007$ for trend) were independent determinants of a deterioration in pegboard performance at altitude.

The 41 subjects retested after return showed no deterioration compared with their baseline times (36.42 $v 36.24$ seconds; $\mathrm{p}=0.68$ ). There was no difference in long term performance between members of climbing teams (all of whom had spent time at $\geqslant 6000 \mathrm{~m}$ ) and the rest of the group (mean deterioration $0.73 v 0.03$ seconds, $\mathrm{p}=0.78$ ) and no correlation between the difference in times between altitude and baseline and age $(r=-0.084, \mathrm{p}=0.6)$.

\section{Discussion}

These findings confirm a deterioration in fine motor function, and add to our knowledge of the effects of age, acclimatisation, and clinical symptoms, on performance at altitude. The deterioration in performance occurred at relatively moderate altitudes, despite slow ascents and may have practical implications for persons engaging in activities relying on high levels of dexterity. Studies at similar altitudes have shown a slowing in motor speed and an increase in inaccuracy. ${ }^{7}$ Although older trekkers have a lower incidence of symptoms of acute mountain sickness, ${ }^{8}$ these data suggest that they are more susceptible to the psychomotor effects of hypoxia at altitude.

There is uncertainty about the extent to which acclimatisation restores neurological function and the delay before this is evident. Early reports describing a prolonged delay to recovery of function; upper limb coordination deteriorated over 10 months in soldiers at $4000 \mathrm{~m}$ after which it gradually improved. ${ }^{7}$ On the other hand, motor function tested in the first day after workers at an observatory had driven up to $4200 \mathrm{~m}$ deteriorated, but normalised on retesting after five days. ${ }^{9}$ This study shows the potential for rapid adaptation at these altitudes and suggests that ascent is associated with a continual process of neurological adaptation.

Identifying predictors of neurological dysfunction at altitude may provide clues to the pathogenesis of this form of hypoxic brain injury and may enable climbers to avoid complications. It has been suggested that climbers with a higher ventilatory response to hypoxia have greater residual neurobehavioural impairment. ${ }^{2}$ In this group, however, there was no correlation between fine motor performance and respiratory function measured on the day of testing. These results show a correlation between AMS symptoms and psychomotor function, similar to that which has been described for performance in some tests of cognitive function. ${ }^{10}$ This relation suggests possible similarities in pathogenesis of acute mountain sickness and psychomotor dysfunction at altitude and stress that particular caution be paid to subjects experiencing even mild symptoms.

Whether exposure to altitude has long term effects on nervous system function remains uncertain. A deterioration in short term verbal recall and motor performance (measured by a finger tapping test) was detected in members of an expedition to Everest immediately after return, which persisted at 1 year. ${ }^{1}$ Similarly, motor performance was poorer than that of matched controls in two of eight climbers who had reached summits of greater than $8500 \mathrm{~m}$ without supplemental oxygen ${ }^{11}$ and reaction times were prolonged in 11 persons tested 75 days after return from an altitude climb. ${ }^{12}$ By contrast, testing of 22 subjects after ascents of between 5334 and $8848 \mathrm{~m}^{3}$ nine subjects after an attempt on Everest, ${ }^{13}$ and six members of a simulated Everest ascent in a hypobaric chamber ${ }^{2}$ could show no significant deterioration in motor function. The present study suggests that people are unlikely to be left with marked residual neurological deficit after exposure to relatively moderate altitudes.

These findings have important practical implications for those spending time at altitude. The improvement in function after a day at a particular altitude emphasises the benefits of adequate acclimatisation. Particular attention should be paid to older persons and those experiencing symptoms of altitude sickness. It is reassuring that the risks of long term upper limb psychomotor dysfunction, at least after exposure to moderate altitude, seem to be small.

I am grateful to "Medical expeditions", the organisers of the trip and to all expedition members who agreed to be tested; Dr Pam Sonnenberg who assisted with study design and statistical analysis; Dr Helen Weiss for statistical advice; Dr David Collier who coordinated expedition data collection; Dr Jim Milledge and Professor Otto Appenzeller for helpful advice; Professor RAC Hughes for supporting me in undertaking this research project and for critical reading of the manuscript; and Jacqueline Lawson and Henriette van Ruiten who assisted with pegboard testing. Financial support was obtained from the University of Liverpool (the Late Professor Donald Heath) with the help of Liverpool (the Late Professor Donald Heath) with the help of Dr Andrew Pollard and The Special Trustees of St Thomas' Hospital. ES is supported by the Special Trustees of Guy's and
St Thomas' Hospital.

1 West JB. Do climbs to extreme altitude cause brain damage? Lancet 1986;ii:387-8.

2 Hornbein TF, Townes BD, Schoene RB, et al. The cost to the central nervous system of climbing to extremely high the central nervous system of climbing to

3 Clark CF, Heaton RK, Wiens AN. Neuropsychological functioning after prolonged high altitude exposure in mountaineering. Aviat Space Environ Med 1983;54:202-7.

4 Goodkin DE, Hertsgaard D, Seminary J. Upper extremity function in multiple sclerosis: improving assessment sensitivity with box-and-block and nine-hole peg tests. Arch Phys Med Rehabil 1988;69:850-4.

5 Rudick R, Antel J, Confavreux C, et al. Recommendations from the National Multiple Sclerosis Society Clinical Outcomes Assessment Task Force. Ann Neurol 1997;42:37982.

6 Roach RC, Bärtsch P, Hackett PH, et al. The Lake Louise acute mountain sickness scoring system. In: Sutton JR, Houston CS and Coates G, eds. Hypoxia and mountain medicine. Burlington, VA: Queen City Printers, 1992: medicine.

7 Sharma VM, Malhotra MS, Baskaran AS. Variations in psychomotor efficiency during prolonged stay at high altitude. Ergonomics 1975;18:511-16. 
8 Hackett PH, Rennie D. The incidence, importance, and prophylaxis of acute mountain sickness. Lancet 1976;ii: 1149-55.

9 Forster P. Telescopes in high places. In: Heath D, ed. Aspects of hypoxia. Liverpool: Liverpool University Press, 1986:

10 Shukitt-Hale B, Banderet LE, Lieberman, HR. Relationships between symptoms, moods, performance, and acute mountain sickness at 4700 meters. Aviat Space Environ Med 1991;62:865-9.
11 Regard M, Oelz O, Brugger $\mathrm{P}$, et al. Persistent cognitive impairment in climbers after repeated exposure to extreme impairment in climbers after repeate

12 Cavaletti G, Tredici G. Long-lasting neuropsychological changes after a single high altitude climb. Acta Neurol Scand 1993;87:103-5

13 Jason GW, Pajurkova EM, Lee RG. High-altitude mountaineering and brain function: neuropsychological testing of members of a Mount Everest expedition. Aviat Space Environ Med 1989;60:170-3. 